\title{
Resistance to recombinant human erythropoietin due to aluminium overload and its reversal by low dose desferrioxamine therapy
}

\author{
M. Yaqoob, R. Ahmad, P. McClelland, K.A. Shivakumar, D.F. Sallomi, \\ I.H. Fahal, N.B. Roberts ${ }^{1}$ and T. Helliwell ${ }^{2}$ \\ Departments of Renal Medicine, ${ }^{1}$ Chemical Pathology and ${ }^{2}$ Pathology, Royal Liverpool University \\ Hospital, UK
}

\begin{abstract}
Summary: Seventeen severely anaemic and transfusion-dependent haemodialysis patients with a haemoglobin less than $7 \mathrm{~g} / \mathrm{dl}$ were treated with recombinant human erythropoietin (r-Hu-EPO). Aluminium toxicity was diagnosed by a positive desferrioxamine (DFO) test and bone biopsy. Seven out of eight patients without aluminium toxicity responded to r-Hu-EPO therapy. Similarly all patients with aluminium toxicity $(n=4)$ but pre-treated with standard dose of DFO prior to r-Hu-EPO therapy responded but none of the patients with untreated aluminium toxicity $(n=5)$ responded to r-Hu-EPO therapy. In order to achieve adequate response in these patients, r-Hu-EPO and DFO had to be given in combination. The dose of desferrioxamine used to reverse r-Hu-EPO resistance was less and also used for a short time. We therefore confirm r-Hu-EPO resistance owing to aluminium overload and report its successful and safe reversal with low dose DFO therapy.
\end{abstract}

\section{Introduction}

Erythropoietin deficiency has been incriminated as a principal cause of anaemia in patients receiving regular dialysis therapy (RDT). ${ }^{1-2}$ Recombinant human erythropoietin (r-Hu-EPO) has been used successfully in the treatment of anaemia of end stage renal disease in over $90 \%$ of patients on dialysis. ${ }^{3-5}$ Some treatment failures are undoubtedly due to subtle blood loss or haemolysis, secondary hyperparathyroidism ${ }^{2}$ and unrecognized iron deficiency. ${ }^{6}$ Aluminium intoxication may also occur in RDT patients (brought about by the chronic ingestion of aluminium-containing phosphate binders or with the use of untreated haemodialysis water) and cause microcytic, hypochromic or normochromic anaemia ${ }^{7,8}$ which is a recognized cause of r-Hu-EPO resistance., ${ }^{9,10}$ Aluminium-related anaemia can be successfully reversed by chelation of aluminium with DFO. ${ }^{11-13}$ However, the DFO dosage used has been high and can result in serious ocular and haemodynamic side effects. ${ }^{14-16}$ It is not known whether DFO administration would reverse r-Hu-EPO resistance when used in small doses either prior to, or simultaneously with r-Hu-EPO treatment. We report

Correspondence: M. Yaqoob, M.R.C.P.(UK), 6Z Link Unit, Royal Liverpool University Hospital, Prescot Street, Liverpool L7 8XP, UK.

Accepted: 24 August 1992 our experience of r-Hu-EPO administration patients on RDT with and without aluminium toxicity.

\section{Patients and methods}

Seventeen severely anaemic and transfusiondependent patients on RDT with haemoglobin (Hb) less than $7 \mathrm{~g} / \mathrm{dl}$ were treated with $\mathrm{r}-\mathrm{Hu}-\mathrm{EPO}$ Aluminium overload was diagnosed or excluded by a positive low-dose DFO aluminium mobilization test $^{17}$ (all patients) and bone biopsy (12 patients) performed 2-4 weeks prior to r-Hu-EPO therapy as a part of baseline investigations.

Serum aluminium levels were measured by DC plasma emission spectrometry. ${ }^{18}$ Twelve patients had a transiliac bone biopsy after double tetracycline labelling. ${ }^{19}$ Bone histomorphometric analysis was done using standard techniques. ${ }^{20-22}$ Biopsy specimens were fixed in absolute alcohol 'Analar' before processing, sectioning and staining with van Geison stain to show osteoid and the soluchrome azurine method ${ }^{22}$ for aluminium. The presence of ferric iron was excluded by using Perl's stain. Morphometry was performed using Kontron MOP-30 image analysis system and digitizing tablet. Aluminium-related bone disease was diagnosed by using the criteria similar to those used by others. ${ }^{20,21}$ Eight patients (five males) in the study 
had no evidence of aluminium toxicity (four also had a negative bone biopsy) and comprised Group 1. The remaining nine patients (four males) who were aluminium toxic (eight had a positive bone biopsy) were subdivided into two groups, Group 2 $(n=5)$ who prior to r-Hu-EPO therapy were not treated for aluminium toxicity and Group $3(n=4)$ who had been treated by DFO ( $1 \mathrm{~g}$ intravenously three times weekly on dialysis for 6 months) before $\mathrm{r}-\mathrm{Hu}-\mathrm{EPO}$ therapy was commenced because of the severity of musculo-skeletal symptoms. After 6 months of DFO therapy, a repeat DFO test performed before the commencement of r-Hu-EPO therapy was negative in each case. Salient clinical features and base line investigations of the patients are summarized in Table $I$.

All patients received $\mathrm{r}-\mathrm{Hu}-\mathrm{EPO} 50 \mathrm{U} / \mathrm{kg}$ body weight intravenously at the end of each dialysis session (duration 4 hours three times weekly). The dose was increased by $25 \mathrm{U} / \mathrm{kg}$ body weight every 4 weeks until $100 \mathrm{U} / \mathrm{kg}$ body weight or haemoglobin (Hb) concentration of more than $9 \mathrm{~g} / \mathrm{dl}$ was achieved. The study period lasted for 12 weeks. The DFO dose used for the treatment of aluminium toxicity was $1 \mathrm{~g}$ intravenously over the last 2 hours of each dialysis session for 6 months. Iron deficiency detected by serum ferritin $<100 \mu \mathrm{g} / 1$ and transferrin saturation $<20 \%{ }^{23,24}$ was treated by intravenous iron dextran (100 mg elemental iron) once a week. Patients from the three groups continued to take their usual medication which included antihypertensive drugs, phosphate binders (calcium carbonate and aluminium hydroxide), one alpha cholecalciferol, and oral iron and vitamin supplements. Iron supplements were doubled before the start of the study in all but one patient who was iron overloaded (serum ferritin $>9,000 \mu \mathrm{g} / \mathrm{l}$ ).

The haematological profile was measured twice as a baseline before starting r-Hu-EPO therapy and thereafter once weekly before dialysis during the study period. Serum iron, total iron binding capacity and serum ferritin were done before and repeated at monthly intervals during r-Hu-EPO administration.

\section{Results}

All but one patient in Group 1 responded well to $\mathrm{r}-\mathrm{Hu}$-EPO therapy and within 12 weeks reached the target $\mathrm{Hb}$ greater than $9 \mathrm{~g} / \mathrm{dl}$. The unresponsive patient in this group had florid hyperparathyroid disease. Patients from Group 3, who were aluminium toxic and were first treated by DFO for 6 months, responded during DFO chelation therapy with transient improvement in their anaemia. Pre-DFO $\mathrm{Hb}(\mathrm{g} / \mathrm{dl}) 5.2 \pm 0.67$ rose to $7.4 \pm 0.24$ at the end of 6 months DFO therapy but became anaemic again with $\mathrm{Hb}$ falling to $6.6 \pm 0.37$ 2 months after stopping the DFO therapy. Group 3 patients when treated subsequently with r-Hu-EPO alone, achieved the target $\mathrm{Hb}$ like Group 1 patients within 12 weeks. The five patients in Group 2 who were not pretreated with DFO did not achieve the target haemoglobin. Moreover, the mean rise of $\mathrm{Hb}$ above baseline within the study period in

Table I Salient clinical and laboratory details of study population (results given as mean \pm SEM)

\begin{tabular}{lccc}
\hline Variables & Group 1 & Group 2 & Group 3 \\
\hline $\begin{array}{l}\text { Age (years) } \\
\text { Duration of RTD } \\
\text { (years) }\end{array}$ & $52 \pm 5.9$ & $52 \pm 6.8$ & $40 \pm 1.3$ \\
Baseline & & $7.2 \pm 1.8$ & $14.7 \pm 1.9$ \\
Hb (g/dl) & $5.8 \pm 0.3$ & $5.7 \pm 0.5$ & $6.2 \pm 0.4$ \\
Ferritin $(\mu \mathrm{g} / \mathrm{l})$ & $571 \pm 123$ & $430 \pm 100$ & $438 \pm 87^{*}$ \\
PTH (pmol/l) & $250 \pm 122$ & $538 \pm 207$ & $520 \pm 277$ \\
DFO test & $61 \pm 7.8$ & $93 \pm 17.3$ & $63 \pm 24.2 \dagger$ \\
t1 & $82.5 \pm 8.9$ & $201 \pm 25.7$ & $86 \pm 35.2 \dagger$ \\
t2 & $24.5 \pm 5.1$ & $108 \pm 15.6$ & $22.5 \pm 11 \dagger$ \\
t2-t1 (A1 rise) & & & \\
Post r-Hu-EPO & $9.6 \pm 0.5$ & $6.9 \pm 0.5$ & $10.4 \pm 0.7$ \\
Hb (g/dl) $\ddagger$ & $336 \pm 95.6$ & $230 \pm 77$ & $267 \pm 73.3^{*}$ \\
Ferritin $(\mu \mathrm{g} / \mathrm{l})$ & & \\
\hline
\end{tabular}

$\nmid$ Excluding iron overloaded patient; †corresponding values of DFO test pre-DFO therapy in Group 3 were $\mathrm{t} 1=100 \pm 35.5, \mathrm{t} 2=225 \pm 39.3$ and $\mathrm{t} 2-\mathrm{t} 1=125 \pm 14.5$; $\neq$ corresponding $\mathrm{Hb}$ in Group 2 after 12 weeks of combined r-Hu-EPO + DFO therapy $(10.6 \pm 0.3)$; $\mathrm{PTH}=$ parathyroid hormone; DFO = desferrioxamine; r-Hu-EPO = recombinant human erythropoietin; RTD = regular dialysis therapy. 
Group $1(3.62 \pm 0.55)$ and Group $3(4.06 \pm 1.06)$ was significantly higher than in Group 2 $(1.32 \pm 0.28)(P<0.05)$. The rate of rise of haemoglobin in Groups 1 and 3 was also higher than in Group $2(Y=5.53 \pm 0.11 X)$ (Figure 1). There was a significant negative correlation between baseline serum aluminium levels and the mean rise of $\mathrm{Hb}$, and between $\mathrm{Hb}$ rise during $\mathrm{r}-\mathrm{Hu}-\mathrm{EPO}$ therapy and aluminium increment following DFO challenge (Figures 2 and 3), but there was no correlation between baseline parathyroid hormone levels, serum ferritin and the mean $\mathrm{Hb}$ rise during the study period. All patients except one each from Groups 1 and 3 needed to increase the dose of r-Hu-EPO to a maximum of $100 \mathrm{U} / \mathrm{kg}$ body weight during the 12 week study period.

Group 2 patients $(n=5)$ were continued on r-Hu-EPO $100 \mathrm{U} / \mathrm{kg}$ body weight for a further 8 weeks with no improvement in anaemia (12 weeks post $\mathrm{r}-\mathrm{Hu}$-EPO $\mathrm{Hb}(6.9 \pm 0.5) v s$ post 20 weeks $\mathrm{Hb}$ (7.0 \pm 0.38 ). Patients from this group were then treated with combined r-Hu-EPO $(100 \mathrm{U} / \mathrm{kg}$ body

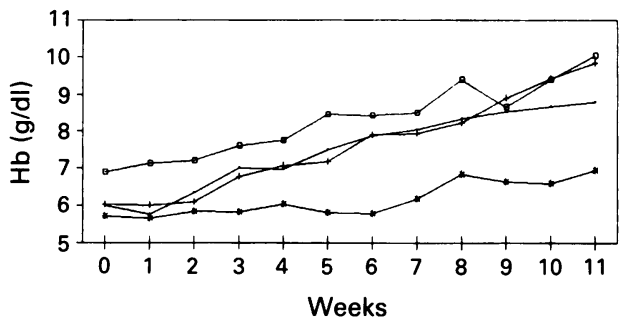

Figure 1 The rate of rise of $\mathrm{Hb}$ in patients from three groups on r-Hu-EPO in Group 2 on combined DFO and r-Hu-EPO therapy. $-1=$ no aluminium; $*$ - $=$ aluminium toxic; $+-+=$ DFO pretreated; $\square-\square=$ DFO and EPO together.

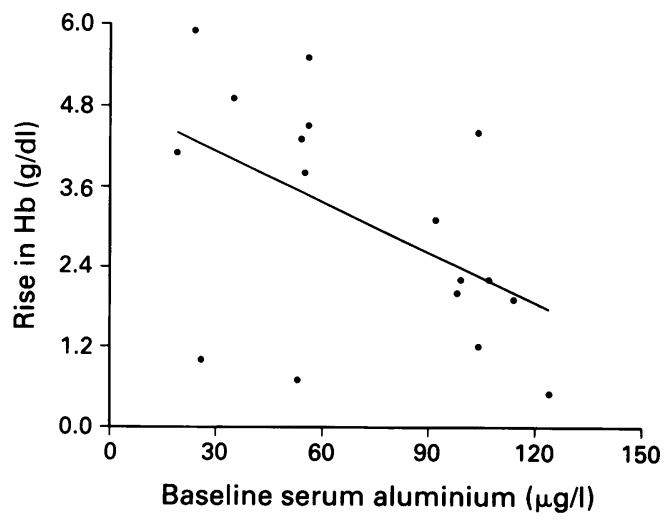

Figure 2 The correlation between baseline serum aluminium levels and $\mathrm{Hb}$ response on $\mathrm{r}-\mathrm{Hu}-\mathrm{EPO}$ therapy $(r=-0.51 ; P=0.03)$.

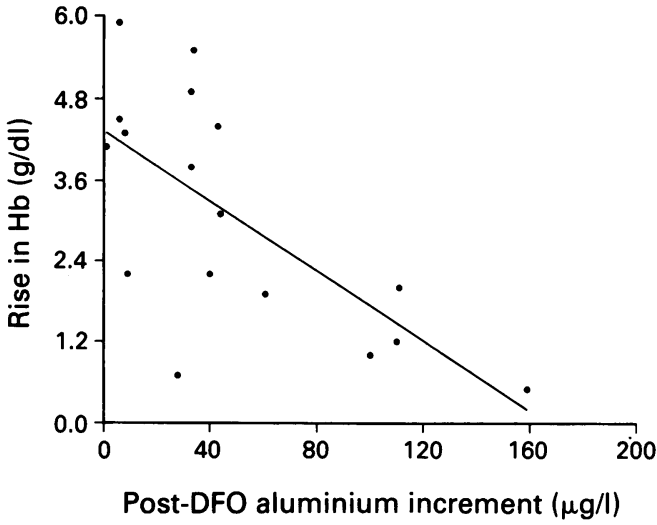

Figure 3 The correlation between post-DFO aluminium increment $(\mathrm{t} 2-\mathrm{t} 1)$ and $\mathrm{Hb}$ reponse on $\mathrm{r}-\mathrm{Hu}-\mathrm{EPO}$ therapy $(r=-0.68 ; P=0.02)$.

weight), DFO (1 $\mathrm{g}$ twice weekly, given intravenously on dialysis) and $100 \mathrm{mg}$ elemental iron once weekly to prevent iron deficiency due to DFO administration. All patients responded to combined therapy and achieved a target $\mathrm{Hb}$ greater than $9 \mathrm{~g} / \mathrm{dl}$ within 12 weeks. The mean $\mathrm{Hb}$ rise on combined r-Hu-EPO and DFO therapy was significantly higher $(3.72 \pm 0.21)$ than with $\mathrm{r}-\mathrm{Hu}$ EPO treatment only $(P<0.01)$. Similarly, the rate of $\mathrm{Hb}$ rise on combined therapy became com parable to Group 1 and Group 3 (Figure 1). The utilization of iron was similar in the three groups (Table I). Four patients became iron deficient on r-Hu-EPO therapy, two each from Group 1 and Group 3 and needed weekly intravenous iron supplements. The iron overloaded patient responded with dramatic fall in serum ferritin levels from $>9,000 \mu \mathrm{g} / 1$ to $<5,000 \mu \mathrm{g} / 1$ within 12 weeks. All patients from the three groups remained transfusion independent during the study period.

\section{Discussion}

All the anaemic patients on regular dialysis therapy responded to r-Hu-EPO therapy (transfusion independent) but the response was not uniform. Patients who were aluminium toxic and not pretreated by DFO, responded poorly and did not achieve the target $\mathrm{Hb}$, furthermore the rate and mean rise of $\mathrm{Hb}$ was significantly less than for patients without aluminium toxicity or those pretreated with DFO for aluminium toxicity. Baeline and post-DFO test aluminium levels correlated negatively to $\mathrm{Hb}$ response, suggestive of its role in erythropoietin resistance which was reversed by either pretreatment with DFO or by combined DFO and r-Hu-EPO therapy. One 
patient from the non-aluminium toxic group failed to achieve the target $\mathrm{Hb}$, but had severe hyperparathyroid bone disease which is a recognized cause of r-Hu-EPO resistance. ${ }^{2}$ However, there was no correlation in this study between baseline parathyroid hormone levels and the degree of response.

Grutzmacher et al..$^{10}$ have previously demonstrated the effect of aluminium overload on the bone marrow response to r-Hu-EPO therapy. In this study patients with higher baseline serum aluminium levels $(>50 \mu \mathrm{g} / \mathrm{l})$ as well as those with post-DFO challenge aluminium rise of $>175 \mu \mathrm{g} / \mathrm{l}$ responded poorly to r-Hu-EPO treatment. The mechanism of aluminium-related anaemia and its partial resistance to r-Hu-EPO therapy remains uncertain. Various proposals have been made, including interference with iron utilization resulting in a reduction in haem synthesis. ${ }^{25}$ Some investigators believe aluminium-related inhibition of aminolaevulinic acid dehydrogenase (ALAD), a key enzyme in haem synthesis, plays an important role in the aluminium-related anaemia. ${ }^{26}$ Erythrocytic protoporphyrin is increased and ALAD activity is reduced in aluminium overload, supporting the enzyme inhibition theory. ${ }^{9}$ Since no measurement of erythrocytic protoporphyrin or ALAD were made in this study no further comments can be made.

Aluminium-related bone disease is treated by DFO administration with a starting dose of $40 \mathrm{mg} /$ $\mathrm{kg}$ body weight and increasing it to $60 \mathrm{mg} / \mathrm{kg}$ body weight and if tolerated by the patients is continued for approximately a year. ${ }^{14}$ Praga et al. ${ }^{13}$ used $2 \mathrm{~g}$ DFO three times a week for 6 months for improvement of anaemia in haemodialysis patients with no evidence of overt aluminium toxicity. Roger et al $^{27}$ have shown that DFO enhances the haemopoietic response to r-Hu-EPO even in patients without aluminium toxicity but DFO dose used was $30 \mathrm{mg} / \mathrm{kg}$ body weight and had to be reduced to $20 \mathrm{mg} / \mathrm{kg}$ because of high incidence of visual toxicity. Similarly, Casati et al. ${ }^{28}$ were able to reduce the maintenance dose of $\mathrm{r}-\mathrm{Hu}$-EPO for necessary haemopoietic response in patients after DFO $(20 \mathrm{mg} / \mathrm{kg}$ body weight/week for 6 months) chelation therapy. In our study DFO dosage used was considerably lower and it was possible to reverse r-Hu-EPO resistance within 12 weeks despite the presence of overt aluminium toxicity. Serious side effects associated with the use of high DFO dosage can be minimized ${ }^{29}$ and were not observed in this study. However, the number of patients in this and other studies ${ }^{27,28}$ were small, owing to a falling incidence of aluminium toxicity in the dialysis population.

The present study has thus identified an inhibitory effect of aluminium on r-Hu-EPO responsiveness in patients with overt aluminium toxicity. The serum aluminium levels $>100 \mu \mathrm{g} / \mathrm{l}$, positive DFO mobilization test and bone biopsy evidence of aluminium overload are predictive of poor responsiveness to $\mathrm{r}-\mathrm{Hu}-\mathrm{EPO}$ therapy. This partial resistance can be reversed by aluminium chelation with minimal DFO either prior to or during r-Hu-EPO therapy. We therefore confirm that aluminium toxicity is an important cause of resistance to r-Hu-EPO therapy and can be reversed safely and successfully by chelation with lose dose DFO treatment.

\section{Acknowledgement}

We thank Cilag Biotech UK for providing r-Hu-EPO for the study.

\section{References}

1. Fisher, J.W. Mechanism of the anaemia of chronic renal failure. Nephron 1980, 25: 106-111.

2. Eschbach, J.W. \& Adamson, J.W. Anaemia of end-stage renal disease (ESRD). Kidney Int 1985, 28: 1-5.

3. Winearls, C.G., Oliver, D.O., Pippard, M.J., Reid, C., Downing, M.R. \& Cotes, P.M. Effect of human erythropoietin derived from recombinant DNA on the anaemia of patients maintained by chronic haemodialysis. Lancet 1986, 2: $1175-1178$.

4. Eschbach, J.W., Egrei, J.C., Downing, M.R., Browne, J.K. \& Adamson, J.W. Correction of the anemia of end stage renal disease with recombinant human erythropoietin. $N$ Engl $J$ Med 1987, 316: 73-78.

5. Canadian Erythropoietin Study Group. Association between recombinant human erythropoietin and the quality of life and exercise capacity of patients receiving haemodialysis. $\mathrm{Br} \mathrm{Med}$ $J$ 1990, 300: 573-578.

6. Macdougall, I., Hutton, R.D., Cavell, I., Coles, G.A. \& Williams, J.D. Poor response to treatment of renal anaemia with erythropoietin corrected by iron given intravenously. $\mathrm{Br}$ Med J 1989, 299: 157-158.

7. McGonigle, R.J.S. \& Parsons, V. Aluminium induced anaemia in haemodialysis patients. Nephron 1985, 39: 1-9.

8. Mladenovic, J. Aluminium inhibits erythropoietin in vitro. $J$ Clin Invest 1988, 81: 1661-1665.

9. Rosenlof, K., Fyhrquist, F. \& Tenhumen, R. Erythropoietin, aluminium and anaemia in patients on haemodialysis. Lancet 1990, 335: 247-249.

10. Grutzmacher, P., Ehmer, B., Messinger, D., Kulbe, K.D. \& Scigalla, P. Effect of aluminium overload on the bone marrow response to recombinant human erythropoietin. Contrib Nephrol 1989, 76: 315-323.

11. Altman, P., Plowman, D., Marsh, F. \& Cunningham, J. Aluminium chelation therapy in dialysis patients: evidence for inhibition of haemoglobin synthesis by low levels of aluminium. Lancet 1988, i: 1012-1015.

12. Short, A.I.K., Winney, R.J. \& Robson, J.S. Reversible microcytic hypochromic anaemia in dialysis patients due to aluminium intoxication. Proc EDTA 1980, 17: 226-233.

13. Praga, M., Andres, A., de la Serna, J. et al. Improvement of anaemia with desferrioxamine in haemodialysis patients. Nephrol Dial Transplant 1987, 2: 243-247. 
14. McCarthy, J.T., Milliner, D.S. \& Johnson, W.I. Clinical experience with desferrioxamine in dialysis patients with aluminium toxicity. $Q J$ Med 1990, 275: 257-276.

15. Milliner, D.S., Nebeker, H.G., Ott, S.M. et al. Use of the desferrioxamine infusion test in the diagnosis of aluminium related osteodystrophy. Ann Intern Med 1984, 101: 775-779.

16. Bene, C., Manzole, A., Bebe, D. \& Kranais, G. Irreversible ocular toxicity from single 'challenge' dose of desferrioxamine. Clin Nephrol 1989, 31: 45-48.

17. Yaqoob, M., Ahmad, R., Roberts, N.B. \& Halliwell, T. Low dose desferrioxamine test for the diagnosis of aluminium bone disease in patients on regular haemodialysis treatment. Nephrol Dial Transplant 1991, 6: 484-486.

18. Roberts, N.B. \& Williams, P. Serum aluminium measurement by DC plasma emission spectrometry. Ann Clin Biochem 1988, 25: 169-175.

19. Hodgson, S.F., Johnson, K.A., Muhs, J.M., Lujkin, E.G. McCarthy, J.T. Outpatient percutaneous biopsy of the iliac crest, methods, morbidity and patient acceptance. Mayo Clin Proc 1986, 61: 28-33.

20. Hodgson, S.F. Skeletal remodelling and renal osteodystrophy. Semin Nephrol 1986, 6: 42-55.

21. McCarthy, J.T., Kurtz, S.B. \& McCall, J.T. Elevated bone aluminium content in dialysis patients without osteomalacia. Mayo Clin Proc 1985, 60: 315-320.
22. Denton, J., Freemont, A.J. \& Ball, J. Detection and distribution of aluminium in bone. $J$ Clin Pathol 1984, 37: 136-142.

23. Macdougall, I., Hutton, R.D., Cavell, I., Coles, G.A. \& Williams, J.D. Treating renal anaemia with recombinant human erythropoietin: practical guidelines and a clinical alogrithim. Br Med J 1990, 300: 655-659.

24. Tomson, C.R.V. Poor response to erythropoietin. Br Med J 1989, 299: 620.

25. Trapp, G.A. Plasma aluminium is bound to transferrin. Life Sci 1983, 33: 311-316.

26. Meredith, P.A., Moore, M.R. \& Goldberg, A. Effect of aluminium, lead and zinc on delta-aminolaevulinic acid dehyratase. Enzyme 1977, 22: 22-27.

27. Roger, S.D., Stewart, J.H. \& Harris, D.C.H. Desferrioxamine enhances the haemopoietic response to erythropoietin, but adverse events are common. Nephron 1991, 58: 33-36.

28. Casati, S., Castelnovo, C., Campise, M. \& Ponticelli, C. Aluminium interference in the treatment of haemodialysis patients with recombinant human erythropoietin. Nephrol Dial Transplant 1990, 5: 441-443.

29. Yaqoob, M., Prabbu, P. \& Ahmad, R. Irreversible ocular toxicity from single challenge dose of desferrioxamine. Clin Nephol 1991, 36: 155. 